Review

\title{
Prevention of Carcinogenesis and Development of Gastric and Colon Cancers by 2-Aminophenoxazine-3-one (Phx-3): Direct and Indirect Anti-Cancer Activity of Phx-3
}

\author{
Akio Tomoda ${ }^{1, *}$, Keisuke Miyazawa ${ }^{1}$ and Takafumi Tabuchi ${ }^{2}$ \\ 1 Department of Biochemistry, Tokyo Medical University, 6-1-1 Shinjuku, Tokyo 160-8402, Japan; \\ E-Mail: miyazawa@tokyo-med.ac.jp \\ 2 Fourth Department of Surgery, Tokyo Medical University, Ibaragi Medical Center, 3-20-1 Chuo, \\ Ami, Inashiki, Ibaraki 300-0395, Japan; E-Mail: tabuchi@tokyo-med.ac.jp \\ * Author to whom correspondence should be addressed; E-Mail: tomoda@tokyo-med.ac.jp; \\ Tel.: +81-3-3351-6141 (ext. 244); Fax: +81-3-3351-6466.
}

Received: 8 July 2013; in revised form: 20 August 2013 / Accepted: 21 August 2013 /

Published: 28 August 2013

\begin{abstract}
Aminophenoxazine-3-one (Phx-3), an oxidative phenoxazine, exerts strong anticancer effects on various cancer cell lines originating from different organs, in vitro. This article reviews new aspects for the prevention of carcinogenesis and development of gastric and colon cancers by $\mathrm{Phx}-3$, based on the strong anticancer effects of Phx-3 on gastric and colon cancer cell lines (direct anticancer effects of Phx-3 for preventing development of cancer), the bacteriocidal effects of Phx-3 against Helicobacter pylori associated with carcinogenesis of gastric cancer (indirect anticancer effects for preventing carcinogenesis of gastric cancer), and the proapoptotic activity of $\mathrm{Phx}-3$ against human neutrophils involved in the incidence of ulcerative colitis associated with a high colon cancer risk (indirect anticancer effects for preventing carcinogenesis of colon cancer).
\end{abstract}

Keywords: Phx-3; gastric and colon cancers; apoptosis; neutrophils

\section{Introduction}

2-Aminophenoxazine-3-one (Phx-3) (Figure 1) was first reported as the antibiotics for streptomyces discovered in soil in Kunitachi, Tokyo, Japan, in 1959 [1]. However, no further characterization of its 
bioactivity was carried out, possibly due to its weaker (and questionable) antibiotic effects against various microbes except for Mycobacterium tuberculosis, and therefore, it was named questiomycin. Tomoda and colleagues found in 1986 [2] that Phx-3 can be produced during the reaction of human erythrocytes or hemoglobin with $o$-aminophenol, and later demonstrated that it does exert strong anticancer effects both on various cancer cell lines [3-8] and cancer cell-transplanted mice in vivo [9,10], as well as antimicrobial effects against Helicobacter pylori [11], Chlamydia pneumoniae [12], some mycobacterial species [13], and herpes viruses [14]. Their studies demonstrated that Phx-3 causes apoptotic cell death in the gastric and colon cancer cell line by decreasing intracellular $\mathrm{pH}$, dysregulating the function of mitochondria, and activating the caspase signaling [8,15-17]. Phx-3 also efficiently suppresses the activity of Akt, which is responsible for the cell survival of cancer cells [7]. These results indicate that Phx-3 has the potential to promote apoptosis of cancer cells, and therefore, may be applied to treat such cancers as gastric cancer and colon cancer, which are refractory to chemotherapy. This article describes the anticancer activity of Phx-3 against gastric and colon cancer cells in terms of preventing the development of gastric and colon cancers (direct effects of Phx-3).

Figure 1. Chemical structure of Phx-3.

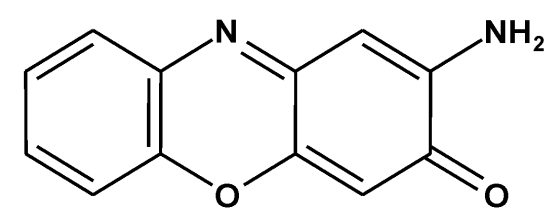

Recent research indicates that inflammation is a critical component of tumor development [18-20], and that neutrophils, which play an important role in the inflammatory reactions in the body, are potentially involved in the carcinogenesis, metastasis and angiogenesis of cancers [21]. In 1992, Tabuchi et al. [22] found that tumor size significantly reduced when neutrophil (=granulocyte) was deleted by extracorporeal circulation after being transplanted with VX2 carcinoma cells, a rabbit papilloma cell line. Later, they demonstrated that neutrophils play a critical role in the development of colon cancer. Namely, using granulocyte apheresis to remove these cells from the blood of patients with colon cancer extensively reduced the size of the cancer, and they proposed that the granulocytes/lymphocytes $(\mathrm{G} / \mathrm{L})$ ratio might be pivotal to the development of colon cancer in the body $[23,24]$. This view has been extensively supported by reports that the increased number of neutrophils in patients with colon cancer is evident [25] and that the G/L ratio in the peripheral blood is significantly higher in the advanced stages of colon cancer [26,27]. In addition, neutrophils that produce a large amount of active oxygen during inflammation are involved in ulcerative colitis and causative of the carcinogenesis of colon cancer [28,29]. Therefore, suppression of the activity of neutrophils may lead to preventing ulcerative colitis, and finally to preventing the carcinogenesis of colon cancer. Recently, Tabuchi et al. [30] found that Phx-3 exerted a strong proapoptotic effect on neutrophils in human blood and almost completely suppressed the generation of superoxide $\left(\mathrm{O}_{2}{ }^{-}\right)$from human neutrophils. Kohno et al. [31] also indicated that Phx-3 has the ability to suppress inflammation, because Phx-3 inhibited the activity of cyclooxygenase-1 (Cox-1) and Cox-2, that of nitric oxide synthetase, and the production of interleukin 6 in macrophages, which are significantly involved in inflammation. Thus, we assumed that the anticancer activity of Phx-3 may be exerted through the suppression of superoxide 
generation and reduction in the number of neutrophils in the peripheral blood in patients with colon cancer, which may be designated as an indirect anticancer activity of Phx-3 for preventing carcinogenesis of colon cancer.

Moreover, $H$. pylori is a major factor in the carcinogenesis of gastric cancer including gastric lymphoma and adenocarcinoma, and abolishing these bacteria from the stomach may reduce the incidence of the gastric cancer [32,33]. Hanawa et al. [11] found that Phx-3 efficiently kills H. pylori, in vitro, which should be regarded as an indirect anticancer activity of Phx-3 on gastric cancer carcinogenesis. These indirect anticancer effects of Phx-3 were analyzed in terms of preventing carcinogenesis of gastric and colon cancers.

\section{Direct Anticancer Activity of Phx-3 on Gastric and Colon Cancers}

Gastric cancer and colon cancer, mostly adenocarcinoma, are refractory to chemotherapy alone [34,35]. Gastric cancer is a common malignancy in Japanese adults and has recently increased in Western adults $[34,36]$. Colon cancer is a major public health problem worldwide, and its incidence is increasing annually [35,37]. In spite of tremendous efforts to prevent the development of gastric and colon cancers, the anticancer drugs to abolish these malignancies are not still developed; thus, surgical therapy is a first-line treatment of these types of cancer. Since we found that Phx-3 extensively prevents the growth of gastric and colon cancer cell lines in vitro [8,15-17], we analyzed its cytotoxic and proapoptotic activities, focusing on the anticancer mechanism for preventing the development of gastric and colon cancer.

\subsection{Cytotoxic and Proapoptotic Effects of Phx-3 on Gastric and Colon Cancer Cells in Vitro}

Kasuga et al. [15] examined the anticancer activity of Phx-3 on human gastric cancer cell lines, MKN45, MKN74, MKN7 and KATO III cells in vitro, and demonstrated that Phx-3 caused cytotoxic ( $50 \%$ inhibition of cell growth, $\mathrm{IC}_{50}$ : less than $10 \mu \mathrm{M}$ ) and proapoptotic effects on these cells at lower concentrations. These cytotoxic effects of Phx-3 were stronger than those of 5-fluorouracil that is clinically administered to patients with the advanced gastric cancer, taking into account the results of Osaki et al. [38] that $1 \mathrm{mM} 5$-fluorouracil induced variable degrees of apoptosis in the cultured gastric cancer cell lines (14\% in MKN74, 12\% in MKN45, 3\% in MKN28 and 0.5\% in KATO-III), and $50 \mu \mathrm{M}$ 5 -fluorouracil had little effect on the induction of apoptosis in these gastric cancer cell lines. In addition, Nakachi et al. [17] studied the anticancer activity of Phx-3 on human colon cancer cell lines, COLO20, DLD1 and PMCO1 cells, and demonstrated that it caused cytotoxic $\left(\mathrm{IC}_{50}\right.$ : less than $\left.10 \mu \mathrm{M}\right)$ and proapoptotic effects on these cells. Cell growth was extensively inhibited by $\mathrm{Phx}-3$ in another colon cancer cell line, Lovo-1 ( $\left.\mathrm{IC}_{50}: 20 \mu \mathrm{M}\right)$, as well [8]. These results indicate that Phx-3 exhibits strong anticancer activity against gastric and colon cancer cells, in vitro. Phx-3 did not affect the growth of the normal cell line-human umbilical vein endothelial cells (HUVECs) - at concentrations less than $60 \mu \mathrm{M}$ [39], suggesting that Phx-3 may exert a less adverse effect on normal cells. 


\subsection{Phx-3 Induces the Apoptotic Cell Death of Gastric and Colon Cancer Cells by Reducing the Higher pHi of These Cells}

Extracellular $\mathrm{pH}$ (pHe) is usually higher than pHi in normal cells, as explained by Donnan's classical membrane equilibrium theory. However, this view does not necessarily explain the extremely acidic $\mathrm{pH}$ in the outer interstitial medium of tumor tissues [40-42]. Therefore, it has been assumed that some mechanism to discharge the hydrogen ion from the cytosol to the extracellular medium might operate in cancer cells. Recent findings indicate that $\mathrm{Na}^{+} / \mathrm{H}^{+}$exchanger isoform 1 (NHE1), which is ubiquitously present in the plasma membrane in normal and cancerous cells, plays a pivotal role in regulating pHi in cancer cells by discharging the cytosolic hydrogen ion to the outside [43-45]. Actually, pHi is more alkaline in cancer cells than in normal cells. Reshkin et al. [46] reported that $\mathrm{pHi}$ is far higher in cancer cells (7.12-7.7) than in normal cells (6.99-7.05). Che et al. [8,47] demonstrated that pHi in more than 10 species of cancer cell lines originating from different organs exceeded 7.4 (pHi in the extreme case was 7.7).

Nagata et al. [16] found that pHi in the human gastric cancer cell lines MKN45 and MKN74 exceeds pHe (pHi of 7.48 for MKN45 and 7.5 for MKN74 cells, versus medium $\mathrm{pH}$ of 7.4). Colon cancer cell line, Lovo-1 cells, exhibited higher $\mathrm{pHi}(\mathrm{pHi}=7.61)$ [7]. Higher $\mathrm{pHi}$ in cancer cells seems to be suitable for proliferation and oncogene transformation of the cells [48,49], and increases tumorigenesis [48-51]. Therefore, agents to reduce $\mathrm{pHi}$ in cancer cells might be promising anticancer drugs, as has been predicted by several researchers [40,46,50]. Nagata et al. [16] demonstrated that when human gastric cancer cells (including MKN45 and MKN74 cells) were treated with Phx-3, pHi decreased rapidly, dependent on the dose of Phx-3, and such intracellular acidification was sustained for at least $4 \mathrm{~h}$. In particular, pHi decreased by $1.6 \mathrm{pH}$ units in MKN45 cells and 1.2pH units in MKN74 cells immediately after administration of $100 \mu \mathrm{M}$ Phx-3. Such rapid and drastic changes in $\mathrm{pHi}$ in these gastric cancer cells could be explained by the inhibition of NHE1 caused by administering Phx-3. A close relationship between anticancer activity of Phx-3 on these gastric cell lines and a decreased extent of pHi caused by Phx-3 was shown [16]. It also confirmed a causal relationship between $\Delta \mathrm{pHi}$ and cytotoxic effects due to Phx-3 in various cancer cell lines [8].

An extensive pHi decrease may promote proapoptotic signaling in gastric and colon cancer cells. Specifically, the decrease of $\mathrm{pHi}$ activates caspase-3, an important executor of apoptosis, and DNase II, a $\mathrm{pH}$-dependent endonuclease that is responsible for DNA fragmentation, thus inducing apoptotic cell death of these cancer cells [52,53]. This view is consistent with a report by Perez-Sala et al. [54] that when HL-60 cells (a human leukemia cell line) were treated with either ionomycin or lovastatin, cellular apoptosis was induced as a result of intracellular acidification and activation of DNase II.

The mechanism by which Phx-3 inhibits NHE1 may be explained by the findings of Hendrich et al. [55] that phenoxazine molecules are located close to the polar/apolar interface of lipid bilayers and weakly interact with lipid bilayers, altering the lipid phase properties of the cellular membranes. It is possible that rapid changes in the conditions of the plasma membranes induced by Phx-3 significantly affect the activity of NHE1 in the cellular membranes. It is noteworthy that the action of Phx-3 seems to be opposite to that of 12-O-tetradecanoylphorbol-13-acetate (TPA), a strong cancer promoter that interacts with phospholipid bilayers to increase pHi. This view is consistent with the findings of Azuine et al. [56] that the cancer promotion action of TPA was cancelled by the phenoxazine compounds. 


\subsection{Dysfunction of the Mitochondria in Gastric and Colon Cancer Cells by Phx-3}

Depolarization of mitochondria is an eminent change that activates caspases and greatly influences the apoptotic events in cancer cells [52,53]. In gastric and colon cancer cells, treatment with Phx-3 significantly depolarizes mitochondria, followed by apoptotic cell death of these cancer cells $[8,16]$. This result is consistent with recent reports $[6,8]$ that $\mathrm{Phx}-3$ depolarizes mitochondria in a variety of cancer cell lines originating from different organs. Therefore, Phx-3 may exert strong anticancer activity on gastric and colon cancers via depolarization of mitochondria in these cells.

\subsection{Plausible Mechanism for the Anticancer Effects of Phx-3 on Gastric and Colon Cancer Cells}

The proapoptotic activity of Phx-3 may be explained by the mechanism depicted in Scheme 1. First, Phx-3 may inhibit the activity of NHE1 and cause a drastic reduction of pHi in gastric and colon cancer cells, which activates caspase-3 and DNase II that are responsible for apoptotic cell death signaling in these cells.

Scheme 1. Plausible mechanism for anticancer effects of Phx-3 on gastric and colon cancer cells.

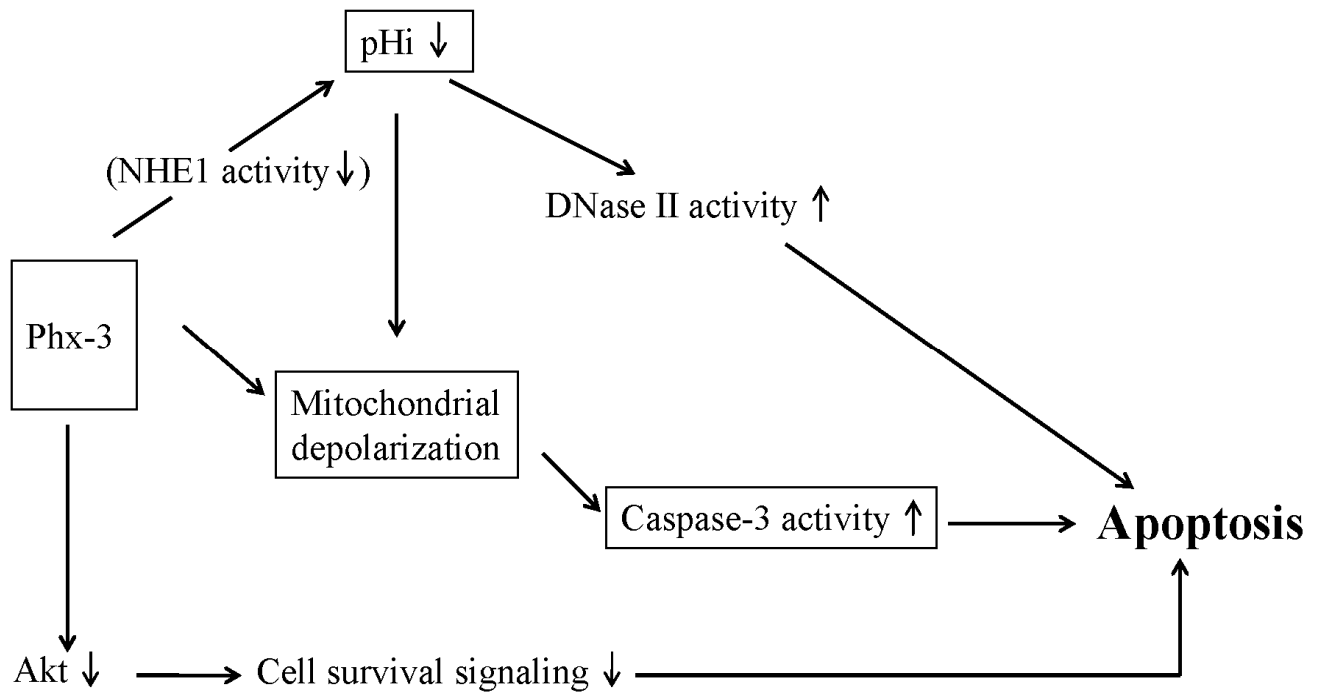

Serine/threonine kinase Akt mediates a variety of survival signaling, participating in the growth factor maintenance of cell survival and preventing cancer cells from becoming apoptotic. Therefore, it is important to suppress Akt signaling to prevent the survival of cancer cells, and agents to inhibit activity of Akt may be promising for cancer chemotherapy. Enoki et al. [57] initially reported the significant activity of Phx-1 (2-amino-4,4 $\alpha$-dihydro-4 $\alpha, 7$-dimethyl-3H-phenoxazine-3-one), another oxidative phenoxazine, in suppressing the phosphorylation of Akt in rat basophilic leukemia RBL-2H3 cells. Hara et al. [58] demonstrated that Phx-1 inhibits the proliferation and serum-induced phosphorylation of Akt in Jurkat cells, a human T cell leukemic cell line. Thimmaiah et al. [59] examined in detail the effect of various synthetic phenoxazines and demonstrated that $N^{10}$-substituted phenoxazines such as 10-[4'-(N-diethylamino) butyl]-2-chlorophenoxazine and 10-[4'((beta-hydroxyethyl)piperazineo)butyo]-2-chlorophenoxazine strongly inhibited Akt phosphorylation. Zheng et al. [7] demonstrated that Phx-3 inhibited the phosphorylation of Akt in human lung adenocarcinoma cell line A549 cells, suggesting that Phx-3 strongly suppresses Akt signaling in cancer cells, though it is not clear whether 
Phx-3 inhibits Akt signaling in gastric and colon cancer cells, therefore being still hypothetical. Based on these results, Scheme 1 summarizes the plausible mechanism for Phx-3 inducing apoptosis in cancer cells.

\section{Indirect Anticancer Activity of Phx-3 on Gastric and Colon Cancers}

H. pylori infection is associated with gastric lymphomas and adenocarcinomas, and now is designated as class I carcinogens [32,33]. Therefore, eliminating these bacteria would prevent carcinogenesis of gastric cancer. Hanawa et al. [11] reported that $H$. pylori is sensitive to Phx-3 treatment at a lower concentration of $2 \mu \mathrm{M}$, suggesting that $\mathrm{Phx}-3$ may contribute to preventing carcinogenesis of gastric cancer by killing these bacteria. Overexpression of Cox-2 increases the proliferation of gastric cancer cell lines, and inhibiting Cox-2 slows the growth of stomach cancer xenografts in nude mice [60]. Kohno et al. [31] demonstrated that Phx-3 inhibits Cox-2 in macrophages. Thus, Phx-3 may slow the growth of stomach cancer.

Neutrophils have recently attracted much attention in terms of carcinogenesis, metastasis and angiogenesis of cancers. According to a recent review by Gregori and Houghton [21], neutrophils influence inflammatory cell recruitment and activation by producing cytokines and chemokines, and regulate tumor cell proliferation, angiogenesis, and metastasis by secreting reactive oxygen species (ROS) and proteases. Thus, the manipulating neutrophils may be useful for treating cancers. In 1995, Tabuchi et al. [23] first indicated that neutrophils play a critical role in the development of colon cancer, because using granulocyte apheresis to remove these cells from the blood of patients with colon cancer extensively reduced the cancer size. Shimazaki et al. [61] also indicated that the G/L ratio is clinically relevant biomarker of long-term cancer progression in patients with colorectal cancer. Therefore, drugs that selectively decrease the number of circulating neutrophils in the blood may be beneficial for treating colon cancer. The recent discovery of Tabuchi et al. [30] that when freshly obtained blood was treated with $50 \mu \mathrm{M} \mathrm{Phx}-3$ at $37^{\circ} \mathrm{C}$ for $18 \mathrm{~h}$, the population of apoptotic neutrophils increased to more than $50 \%$, but no apoptotic lymphocytes were seen, may be of significance in treating colon cancer. This would be designated as an indirect anticancer effect of $\mathrm{Phx}-3$ on colon cancer.

Neutrophils seem to be involved in ulcerative colitis, which is associated with the carcinogenesis of colon cancer $[28,29]$. Neutrophils, which produce a large amount of active oxygen during inflammation [62,63], may be associated with the onset of ulcerative colitis [28,29], therefore, suppression of neutrophil activity may lead to preventing ulcerative colitis, and finally to preventing the carcinogenesis of colon cancer. Phx-3 may be a promising drug for treating ulcerative colitis because it almost completely suppressed generation of superoxide $\left(\mathrm{O}_{2}{ }^{-}\right)$from human neutrophils in vitro [30]. Such indirect anticancer effects of Phx-3 on carcinogenesis of colon cancer should be confirmed by further experiments using animals.

\section{Future Aspect of Phx-3 as Anticancer Drug for the Treatment of Gastric and Colon Cancers}

In this review, we surveyed the direct and indirect anticancer activity of Phx-3 on gastric and colon cancer; however, these findings should be confirmed in experiments using animals. Though we did not apply Phx-3 to mice with gastric or colon cancer, we found that Phx-3 extensively suppressed the development and metastasis of malignant melanoma cells transplanted in mice $[9,10]$. The results of the panel test conducted by Miyake et al. [64] may suggest the availability of Phx-3 to humans, because they 
demonstrated that when the patients with gastritis were administered with the tablet $(200 \mathrm{mg})$ containing $1 \mu \mathrm{g}$ Phx-3 after each dinner for one week, their gastric conditions were much improved, as evaluated based on the patients' conditions of the stomach, in comparison with the control patients without administration of the tablet. Also, Phx-3 had few adverse effects on mice at higher doses $[9,10]$. Kohno et al. [31] reported that oral administration of $500-1500 \mathrm{mg} / \mathrm{kg} \mathrm{Phx}-3$ to ddY mice did not cause gastrointestinal injury and that repeated oral administration of $10 \mathrm{mg} / \mathrm{kg}$ Phx-3 to mice for four weeks caused no diarrhea. Therefore, it would be significant to investigate whether or not Phx-3 holds promise as an agent to treat human gastric and colon cancer.

\section{Acknowledgments}

The present research was supported in part by funds from the Private University Strategic Research-Based Support Project (Molecular Information-based Intractable Disease Research Project) from the Ministry of Education, Culture, Sports, Science and Technology of Japan (2008-2012).

\section{Conflicts of Interest}

The authors declare no conflict of interest.

\section{References}

1. Anzai, K.; Isono, K.; Okuma, K.; Suzuki, S. The new antibiotics, questiomycins A and B. J. Antibiotics 1960, 13, 125-132.

2. Tomoda, A.; Yamaguchi, J.; Kojima, H.; Amemiya, H.; Yoneyama, Y. Mechanism of o-aminophenol metabolism in human erythrocytes. FEBS Lett. 1986, 196, 44-48.

3. Shimizu, S.; Suzuki, M.; Miyazawa, K.; Yokoyama, T.; Ohyashiki, K.; Miyazaki, K.; Abe, A.; Tomoda, A. Differentiation and apoptosis in human malignant melanoma G-361 cells induced by 2-aminophenoxazine-3-one. Oncol. Rep. 2005, 14, 41-46.

4. Kato, S.; Shirato, K.; Imaizumi, K.; Toyota, H.; Mizuguchi, J.; Odawara, M.; Che, X-F.; Akiyama, S.; Abe, A.; Tomoda, A. Anticancer effects of phenoxazine derivatives combined with tumor necrosis factor-related apoptosis-inducing ligand on pancreatic cancer cell lines, KLM-1 and MIA-PaCa-2. Oncol. Rep. 2006, 15, 843-848.

5. Shirato, K.; Imaizumi, K.; Miyazawa, K.; Takasaki, A.; Mizuguchi, J.; Che, XF.; Akiyama, S.; Tomoda, A. Apoptosis induction preceded by mitochondrial depolarization in multiple myeloma cell line U266 by 2-aminophenoxazine-3-one. Biol. Pharm. Bull. 2008, 31, 62-67.

6. Takasaki, A.; Hanyu, H.; Iwamoto, T.; Shirato, K.; Izumi, R.; Toyota, H.; Mizuguchi, J.; Miyazawa, K.; Tomoda, A. Mitochondrial depolarization and apoptosis associated with sustained activation of c-jun- $N$-terminal kinase in the human multiple myeloma cell line U266 induced by 2-aminophenoxazine-3-one. Mol. Med. Rep. 2009, 2, 199-203.

7. Zheng, C.L.; Che, X.-F.; Akiyama, S.; Miyazawa, K.; Tomoda, A. 2-Aminophenoxazine-3-one induces cellular apoptosis by causing rapid intracellular acidification and generating reactive oxygen species in human lung adenocarcinoma cells. Int. J. Oncol. 2010, 36, 641-650. 
8. Che, X.F.; Zheng, C.L.; Akiyama, S.; Tomoda, A. 2-Aminophenoxazine-3-one and 2-amino4,4 $\alpha$-dihydro-4 $\alpha, 7$-dimethyl-3H-phenoxazine-3-one cause cellular apoptosis by reducing higher intracellular pH in cancer cells. Proc. Jpn. Acad. Ser. B 2011, 87, 199-213.

9. Miyano-Kurosaki, N.; Kurosaki, K.; Hayashi, M.; Takaku, H.; Hayafune, M.; Shirato, K.; Kasuga, T.; Endo, T.; Tomoda, A. 2-Aminophenoxazine-3-one suppresses the growth of mouse malignant melanoma B16 cells transplanted into C57BL/6Cr Slc mice. Biol. Pharm. Bull. 2006, 29, 2197-2201.

10. Hongo, T.; Miyano-Kurosaki, N.; Kurosaki, K.; Hata, A.; Tomoda, A. 2-Aminophenoxazine-3-one prevents pulmonary metastasis of mouse B16 melanoma cells in mice. J. Pharmacol. Sci. 2010, 114, 63-68.

11. Hanawa, T.; Osaki, T.; Manzoku, T.; Fukuda, M.; Kawakami, H.; Tomoda, A.; Kamiya, S. In vitro antibacterial activity of Phx-3 against Helicobacter pylori. Biol. Pharm. Bull. 2010, 33, 188-191.

12. Uruma, T.; Yamaguchi, H.; Fukuda, M.; Kawakami, H.; Goto, H.; Kishimoto, T.; Yamamoto, Y.; Tomoda, A.; Kamiya, S. Chlamydia pneumoniae growth inhibition in human monocytic THP-1 cells and human epithelial HEp-2 cells by a novel phenoxazine derivative. J. Med. Microbiol. 2005, 54, 1143-1149.

13. Shimizu, S.; Suzuki, M.; Tomoda, A.; Arai, S.; Taguchi, H.; Hanawa, T.; Kamiya, S. Phenoxazine compounds produced by the reactions with bovine hemoglobin show antimicrobial activity against non-tuberculosis mycobacteria. Tohoku J. Exp. Med. 2004, 203, 47-52.

14. Hayashi, K.; Hayashi, T.; Tomoda, A. Phenoxazine derivatives inactivate human cytomegalovirus, herpes simplex virus-1, and herpes simplex virus-2 in vitro. J. Pharmacol. Sci. 2008, 106, 369-375.

15. Kasuga, T.; Tabuchi, T.; Shirato, K.; Imaizumi, K.; Tomoda, A. Caspase-independent cell death revealed in human gastric cancer cell lines, MKN45 and KATO III treated with phenoxazine derivatives. Oncol. Rep. 2007, 17, 400-415.

16. Nagata, H.; Che, X.-F.; Miyazawa, K.; Tomoda, A.; Konishi, M.; Ubukata, H.; Tabuchi, T. Rapid decrease of intracellular $\mathrm{pH}$ associated with inhibition of $\mathrm{Na}^{+} / \mathrm{H}^{+}$exchanger precedes apoptotic events in the MNK45 and MNK74 gastric cancer cell lines treated with 2-aminophenoxazine-3-one. Oncol. Rep. 2011, 25, 341-346.

17. Nakachi, T.; Tabuchi, T.; Takasaki, A.; Arai, S.; Miyazawa, K.; Tomoda, A. Anticancer activity of phenoxazines produced by bovine erythrocytes on colon cancer cells. Oncol. Rep. 2010, 23, 1517-1522.

18. Balkwill, F.; Mantovani, A. Inflammation and cancer: Back to Virchow? Lancet 2001, 37, 539-545.

19. Coussens, L.M.; Werb, Z. Inflammation and cancer. Nature 2002, 430, 860-867.

20. Richards, C.H.; Roxburgh, C.S.; Anderson, J.H.; McKee, R.F.; Foulis, A.K.; Horgan, P.G.; McMillan, D.C. Prognostic value of tumour necrosis and host inflammatory responses in colorectal cancer. Br. J. Surg. 2012, 99, 287-294.

21. Gregori, A.; Houghton, A. Tumor-associated neutrophils: New targets for cancer therapy. Cancer Res. 2011, 71, 2411-2416.

22. Tabuchi, T.; Soma, T.; Yonekawa, M.; Komai, T.; Hashimoto, T.; Adachi, M. Reduction of VX2 transplanted tumor by granulocyte depletion using extracorporeal circulation on rabbit models. Anticancer Res. 1992, 12, 795-798. 
23. Tabuchi, T.; Ubukata, H.; Sato, S.; Nakata, I.; Goto, Y.; Watanabe, Y.; Hashimoto, T.; Mizuta, T.; Adachi, M.; Soda, T. Granulocytapheresis as a possible cancer treatment. Anticancer Res. 1995, 15, 985-990.

24. Tabuchi, T.; Ubukata, H.; Saniabadi, A.; Soma, T. Granulocyte apheresis as a possible new approach in cancer therapy: A pilot study involving two cases. Cancer Detect. Prev. 1999, 23, 417-421.

25. Satomi, A.; Murakami, S.; Ishida, K.; Matsuri, M.; Hashimoto, T.; Sonoda, M. Significance of increased neutrophils in patients with advance colorectal cancer. Acta Oncol. 1995, 34, 69-73.

26. Chua, W.; Charles, K.A.; Baracos, V.E.; Clarke, S.J. Neutrophil/lymphocyte ratio predicts chemotherapy outcomes in patients with advanced colorectal cancer. Brit. J. Cancer 2011, 104, 1288-1295.

27. Rao, H.L.; Chem, J.W.; Fu, X.J.; Zeng, Y.X.; Cai, M.Y.; Xie, D. Increased intratumoral neutrophil in colorectal carcinomas correlates closely with malignant phenotype and predicts patients' adverse prognosis. PLoS One 2012, 7, e30806.

28. Stratton, J.; Swanson, P.E.; Upton, M.P. Ulcerative colitis pathology. Available online: http://emedicine.medscape.com/article/2005396-overview (accessed on 26 May 2011).

29. Shang, K.; Bai, U.P.; Wang, C.; Wang, Z.; Yu, H.; Du, X.; Zhou, X.Y.; Chi, Y.U.; Mukaida, N.; Li, Y.Y. Crucial involvement of tumor-associated neutrophils in the regulation of chronic colitis-associated carcinogenesis in mice. PLoS One 2012, 7, e51848.

30. Tabuchi, T.; Che, X.F.; Hiraishi, K.; Adachi, M.; Miyano, K.; Sumimoto, H.; Tabuchi, T.; Miyazawa, K.; Tomoda, A. Selectively induced apoptosis in human neutrophils in the presence of oxidative phenoxazines, 2-amino-4,4 $\alpha$-dihydro-4 $\alpha, 7$-dimethyl-3H-phenoxazine-3-one and 2-aminophenoxazine-3-one, preceded by decrease of intracellular $\mathrm{pH}$, depolarization of the mitochondria, and inhibition of superoxide generation. J. Pharmacol. Sci. 2011, 117, 139-148.

31. Kohno, K.; Miyake, M.; Sano, O.; Tanaka-Kataoka, M.; Yamamoto, S.; Koya-Miyata, S.; Arai, N.; Fujii, M.; Watanabe, H.; Ushio, S.; et al. Anti-inflammatory and immunomodulatory properties of 2-amino-3-phenoxazine-3-one. Biol. Pharm. Bull. 2008, 31, 1938-1943.

32. Bonin, S.; Schwarz, R.E.; Blanke, C.D. Gastric Cancer. In Cancer Management: $A$ Multidisciplinary Approach; Pazdru, R., Coia, L.R., Hoskins, W., Wagman, L.D., Eds.; PPR Inc.: Melville, NY, USA, 2002; pp. 235-247.

33. Sepulveda, A.R. Helicobacter, inflammation, and gastric cancer. Curr. Pathobiol. Rep. 2013, 1, 9-18.

34. Crew, K.N.; Neugut, A.L. Epidemiology of gastric cancer. World J. Gastroenterol. 2006, 12, 354-362.

35. Saliz, L.B.; Cox, J.V.; Blanke, C.; Rosen, L.S.; Fehrenbachr, L.; Moore, M.J.; Maroun, J.A.; Ackland, S.P.; Locker, P.K.; Pirotta, N.; et al. Irinotecan plus fluorouracil and leucovorin for metastatic colorectal cancer. N. Engl. J. Med. 2000, 343, 905-914.

36. Smith, M.G.; Hold, G.L.; Tahara, E.; El-Omar, E.M. Cellular and molecular aspects of gastric cancer. World J. Gastroenterol. 2006, 12, 2979-2990.

37. Dulabh, K.; Monga, M.D.; O'Connell, M.J. Surgical adjuvant therapy for colorectal cancer: Current approaches and future directions. Anal. Surg. Oncol. 2006, 13, 1021-1034. 
38. Osaki, M.; Tanabe, S.; Goto, A.; Hayashi, H.; Oshimura, M.; Ito, H. 5-Fluorouracil (5-FU) induced apoptosis in gastric cancer cell lines: Role of the p53 gene. Apoptosis 1997, 2, 221-226.

39. Fukuda, G.; Yoshitake, N.; Khan, Z.A.; Kanazawa, M.; Notoya, Y.; Che, X.F.; Akiyama, S.; Tomoda, A.; Chakrabarti, S.; Odawara, M. 2-Aminophenoxazine-3-one attenuates glucose-induced augmentation of embryonic form of myosin heavy chain, endothelin-1 and plasminogen activator inhibitor-1 in human umbilical vein endothelial cells. Biol. Pharm. Bull. 2005, 28, 797-801.

40. Izumi, H.; Torigoe, T.; Ishiguchi, H.; Urano, H.; Yoshida, Y.; Tanabe, M.; Ise, T.; Murakami, T.; Yoshida, T.; Nomoto, M.; et al. Cellular pH regulators: Potentially promising molecular targets for cancer therapy. Cancer Treat. Rev. 2003, 29, 541-549.

41. Yamagata, M.; Tannock, I.F. The chronic administration of drugs that inhibit the regulation of intracellular $\mathrm{pH}$ in vitro and anti-tumor effects. Brit. J. Cancer 1996, 73, 1328-1334.

42. Wahl, M.L.; Owen, J.A.; Burd, R.; Herlands, R.A.; Nogami, S.S.; Rodeck, U.; Beerd, D.; Leeper, D.B.; Owen, C.S. Regulation of intracellular $\mathrm{pH}$ in human melanoma: Potential therapeutic implications. Mol. Cancer Ther. 2002, 1, 617-628.

43. Tse, C.M.; Levine, S.A.; Yun, C.H.C.; Brant, S.R.; Nath, S.; Pouyssegur, J.; Donowitz, M. Molecular properties, kinetics and regulation of mammalian $\mathrm{Na}^{+} / \mathrm{H}^{+}$exchangers. Cell. Physiol. Biochem. 1994, 4, 282-300.

44. Putney, L.K.; Denker, S.P.; Barber, D.L. The changing face of the $\mathrm{Na}^{+} / \mathrm{H}^{+}$exchanger, NHE1: Structure, regulation, and cellular actions. Ann. Rev. Pharmacol. Toxicol. 2002, 42, 527-552.

45. Rich, I.N.; Worthington-White, D.; Garden, O.A.; Musk, P. Apopotosis of leukemic cells accompanies reduction in intracellular $\mathrm{pH}$ after targeted inhibition of the $\mathrm{Na}^{+} / \mathrm{H}^{+}$exchanger. Blood 2000, 95, 1427-1434.

46. Reshkin, S.J.; Cardone, R.; Harguindey, S. $\mathrm{Na}^{+}-\mathrm{H}^{+}$exchanger, $\mathrm{pH}$ regulation and cancer. Recent Pat. Anti-Cancer Drug Discovery 2013, 8, 85-99.

47. Che, X.F.; Akiyama, S.; Tomoda, A. Suppression of the proliferation of cancer cell lines, KB-3-1 and $\mathrm{K} 562$ cells preceded by a decrease in intracellular $\mathrm{pH}$ caused by phenoxazine derivative. Oncol. Rep. 2008, 19, 1253-1258.

48. Lagadic-Gossmann, D.; Huc, L.; Lecureur, V. Alteration of intracellular pH homeostasis in apoptosis: Origin and roles. Cell Death Differ. 2004, 11, 953-961.

49. Shrode, L.D.; Tapper, H.; Grinstein S. Role of intracellular $\mathrm{pH}$ in proliferation, transformation and apoptosis. J. Bioenerg. Biomembr. 1979, 29, 293-299.

50. Harguindey, S.; Orive, G.; Pedraz, J.L.; Paradioso, A.; Reshkins, S.J. The role of pH dynamics and the $\mathrm{Na}^{+} / \mathrm{H}^{+}$antiporter in the etiopathogenesis and treatment of cancer. Two faces of the same coin-One single nature. BBA-Rev. Cancer 2005, 1756, 1-24.

51. Harguindey, S.; Arranz, H.; Wahl, M.L.; Orive, G.; Reshkin, S.J. Proton transport inhibitors as potentially selective anticancer drugs. Anticancer Res. 2009, 29, 2127-2136.

52. Matsuyama, S.; Reed, J. Mitochondria dependent apoptosis and cellular pH regulation. Cell Death Differ. 2000, 7, 1155-1165.

53. Matsuyama, S.; Liopis, J.; Deveraux, Q.L.; Tsien, R.Y.; Reed, J.C. Changes in intramitochondrial and cytosolic $\mathrm{pH}$ homeostasis in apoptosis: Early events that modulate caspase activation during apoptosis. Nat. Cell Biol. 2000, 2, 315-325. 
54. Perez-Sala, D.; Collado-Escobar, D.; Mollinedo, F. Intracellular alkalinization suppresses lovastatin-induced apoptosis in HL-60 cells through the inactivation of a pH-dependent endonuclease. J. Biol. Chem. 1995, 270, 6235-6242.

55. Hendrich, A.B.; Stanczak, K.; Komorowska, M.; Motohashi, N.; Kawase, M.; Kichalak, K. A study on the perturbation of model lipid membranes by phenoxazines. Bioorg. Med. Chem. 2006, 14, 5948-5954.

56. Azuine, M.A.; Tokuda, H.; Takayasu, J.; Enjyo, F.; Mukainaka, T.; Konoshima, T.; Nishino, H.; Kapadia, G.J. Cancer chemopreventive effect of phenothiazines and related tri-heterocyclic analogues in the 12-O-tetradecanoylphorbol-13-acetate promoted Epstein-Barr virus early antigen activation and the mouse skin two-stage carcinogenesis models. Pharmacol. Res. 2004, 49, 161-169.

57. Enoki, E.; Sada, K.; Qu, X.; Kyo, S.; Miah, S.M.S.; Hatani, T.; Tomoda, A.; Yamamura, H. The phenoxazine derivative Phx-1 suppresses IgE-mediated degranulation in rat basophilic leukemia RBL-2H3 cells. J. Pharm. Sci. 2004, 94, 329-333.

58. Hara, K.; Okamoto, M.; Aki, T.; Yagita, H.; Tanaka, H.; Mizukami, Y.; Nakamura, H.; Tomoda, A.; Hamasaki, N.; Kang, D. Synergistic enhancement of TRAIL- and tumor necrosis factor $\alpha$-induced cell death by a phenoxazine derivative. Mol. Cancer Ther. 2005, 4, 1121-1127.

59. Thimmaiah, K.N.; Easton, J.B.; Germain, G.S.; Morton, C.L.; Kamath, S.; Buolamwinini, J.K.; Houghton, P.J. Identification of N10 substituted phenoxazines as potential and specific inhibitors of Akt signaling. J. Biol. Chem. 2005, 280, 31924-31935.

60. Fan, X.M.; Jiang, X.H.; Gu, G.; Ching, Y.P.; He, H.; Xia, H.H.X.; Lin, M.C.M.; Chan, A.O.O.; Yen, M.F.; Kung, H.F.; et al. Inhibition of Akt/PKB by a COX-2 inhibitor induces apoptosis in gastric cancer cells. Digestion 2006, 73, 75-82.

61. Shimazaki, J.; Goo, Y.; Nishida, K.; Tabuchi, T.; Motohashi, G.; Ubukata, H.; Tabuchi, T. In patients with colorectal cancer, preoperative serum interleukin-6 level and granulocyte/lymphocyte ratio are clinically relevant biomarkers of long-term cancer progression. Oncology 2013, 84, 356-361.

62. Rossi, F. The $\mathrm{O}_{2}^{-}$-forming NADPH oxidase of the phagocytes: Nature, mechanism of activation and function. Biochim. Biophys. Acta 1986, 833, 65-69.

63. Cross, A.R.; Jones, O.T.G. Enzymic mechanisms of superoxide production. Biochim. Biophys. Acta 1991, 1057, 281-298.

64. Miyake, M.; Kohno, K.; Sano, O. Antiinflammatory agent comprising 2-aminophenol or derivative thereof as active ingredient. Eur. Patents Appl. WO 2008/047758, 24 April 2008.

(C) 2013 by the authors; licensee MDPI, Basel, Switzerland. This article is an open access article distributed under the terms and conditions of the Creative Commons Attribution license (http://creativecommons.org/licenses/by/3.0/). 